\title{
Tecnología lítica e historia ocupacional en Cueva Huenul 1 (localidad Barrancas-Buta Ranquil, provincia del Neuquén, Argentina)
}

\section{Agustina A. Rughini}

Instituto Interdisciplinario de Ciencias Básicas (ICB), Laboratorio de Paleoecología Humana, Facultad de Ciencias Exactas y Naturales, Universidad Nacional de Cuyo (UNCuyo) y Consejo Nacional de Investigaciones Científicas y Técnicas (CONICET). Padre Jorge Contreras 1300, Parque General San Martín (CP 5300), Mendoza, Argentina. E-mail: arughini@mendoza-conicet.gob.ar

\author{
M. de la Paz Pompei \\ (iD) https://orcid.org/0000-0001-8548-390X \\ Instituto Superior de Estudios Sociales (ISES), Universidad Nacional de Tucumán (UNT) y Consejo Nacional de \\ Investigaciones Científicas y Técnicas (CONICET). San Lorenzo 429 (CP 4000), San Miguel de Tucumán, Tucumán,
} Argentina. E-mail: paz.pompei@gmail.com

\section{Karen Borrazzo}

(iD) https://orcid.org/0000-0002-1481-2179

Instituto Multidisciplinario de Historia y Ciencias Humanas (IMHICIHU), Consejo Nacional de Investigaciones Científicas y Técnicas (CONICET). Saavedra 15, $5^{\circ}$ piso (CP C1083ACA), Ciudad Autónoma de Buenos Aires, Argentina. E-mail: kborrazzo@yahoo.com.ar

\section{Ramiro Barberena}

\section{(iD) https://orcid.org/0000-0002-4323-1197}

Instituto Interdisciplinario de Ciencias Básicas (ICB), Laboratorio de Paleoecología Humana, Facultad de Ciencias Exactas y Naturales, Universidad Nacional de Cuyo (UNCuyo) y Consejo Nacional de Investigaciones Científicas y Técnicas (CONICET). Padre Jorge Contreras 1300, Parque General San Martín (CP 5300), Mendoza, Argentina. E-mail: rbarberena@mendoza-conicet.gob.ar

\begin{abstract}
Resumen
Este trabajo presenta el análisis tecno-morfológico de los conjuntos líticos provenientes del sitio arqueológico Cueva Huenul 1 (localidad Barrancas-Buta Ranquil, departamento Pehuenches, provincia del Neuquén, Argentina). El sitio fue ocupado durante el Holoceno temprano (Componente 2) y tardío (Componente 4) por grupos de cazadores-recolectores. Los resultados del estudio comparativo de los materiales líticos de ambos componentes presentan diferencias importantes en densidad, pero no en composición artefactual. En conjunto, el análisis tecno-morfológico sugiere que Cueva Huenul 1 fue ocupada de manera breve y recurrente, aunque discontinua, a través del tiempo. Esto resulta informativo, ya que el contexto de poblamiento en el que se formaron ambos depósitos es muy diferente. Planteamos que esta homogeneidad tecnológica a través del tiempo se puede explicar por la ubicación de $\mathrm{CH} 1$ en cercanía a la cantera de obsidiana Cerro Huenul, y por la distancia con respecto a fuentes permanentes de agua, que en conjunto habrían condicionado pautas semejantes de talla y descarte lítico en el sitio.
\end{abstract}




\title{
Lithic technology and occupational history at Cueva Huenul 1 site (Barrancas-Buta Ranquil, Neuquén, Argentina)
}

\begin{abstract}
In this paper, we present the results of the morpho-technological analysis of lithic assemblages from Cueva Huenul 1 site (Barrancas- Buta Ranquil locality, Pehuenches department, Neuquén Province, Argentina). Hunter-gatherers occupied the site discontinuously during the Early (Component 2) and Late Holocene (Component 4). A comparative analysis of the lithic assemblages assigned to these periods shows that although different in size, they are similar in artifact composition. Furthermore, the morpho-technological analysis suggests that the site was briefly and recurrently occupied, although discontinuously through time. The continuity in the composition of the lithic assemblages is interesting since both components represent different stages in the human peopling of Patagonia. We suggest that the location of $\mathrm{CH} 1$, near the Cerro Huenul obsidian quarry, coupled with the local absence of permanent water sources, may have conditioned this similar pattern of knapping activities and lithic discard at the site.
\end{abstract}

KEYWORDS: Technological strategies; Obsidian; Temporal trends; Northern Patagonia.

\section{Introducción}

La secuencia de ocupaciones humanas en una región ofrece evidencia clave para avanzar en la reconstrucción de procesos en una escala temporal amplia. Dada la limitada disponibilidad de excavaciones sistemáticas acompañadas por programas de datación y análisis de conjuntos artefactuales, muchas veces se deben realizar inferencias sobre la base de escasos puntos con información adecuada. Esto resulta particularmente usual en referencia a las instancias iniciales del proceso de colonización humana del continente, que tienen tanto un menor potencial de incorporación en el registro arqueológico como de interceptación en el muestreo actual (Borrero, 2016). En determinadas regiones que han sido poco investigadas a través del tiempo, como el noroeste de Patagonia, esta situación es particularmente marcada.

En este trabajo se presentan los resultados del análisis de los conjuntos líticos provenientes del sitio Cueva Huenul 1 (en adelante $\mathrm{CH} 1$ ), ubicado en el norte de la provincia del Neuquén, Argentina (Figura 1). Dado que este sitio ofrece una secuencia crono-estratigráfica que abarca en forma discontinua los últimos 15000 años calendáricos (Barberena et al., 2015; Pompei et al., 2012), sus aportes resultan ser de importancia clave para la reconstrucción de múltiples períodos de ocupación humana a nivel local y regional, los que se utilizan en conjunto con cuerpos de datos disponibles para regiones vecinas (Campbell, Moya Cañoles y Gutiérrez, 2020; Crivelli Montero et al., 1996; Hajduk, Albornoz y Lezcano, 2011; Neme y Gil, 2008; Rindel, Pérez y Romero Villanueva, 2018, entre otros).

El objetivo general de este trabajo consiste en evaluar la ocurrencia de cambios en los modos en que $\mathrm{CH} 1$ fue utilizado a través del tiempo, mediante el estudio de las pautas de descarte de artefactos líticos. Sobre esta base y a partir del análisis tecnomorfológico, se aborda la historia de la organización de la tecnología lítica y las estrategias implementadas por los grupos humanos que habitaron la localidad (Binford, 1980; Kuhn, 2004; Nelson, 1991). Para ello se comparan dos bloques temporales con presencia humana que representan los extremos en la secuencia de colonización regional (ca. 11000-10000 y 1600-400 años cal. AP). Este sitio se localiza en los denominados 'espacios bajos' de la localidad Barrancas-Buta Ranquil, la cual es foco 


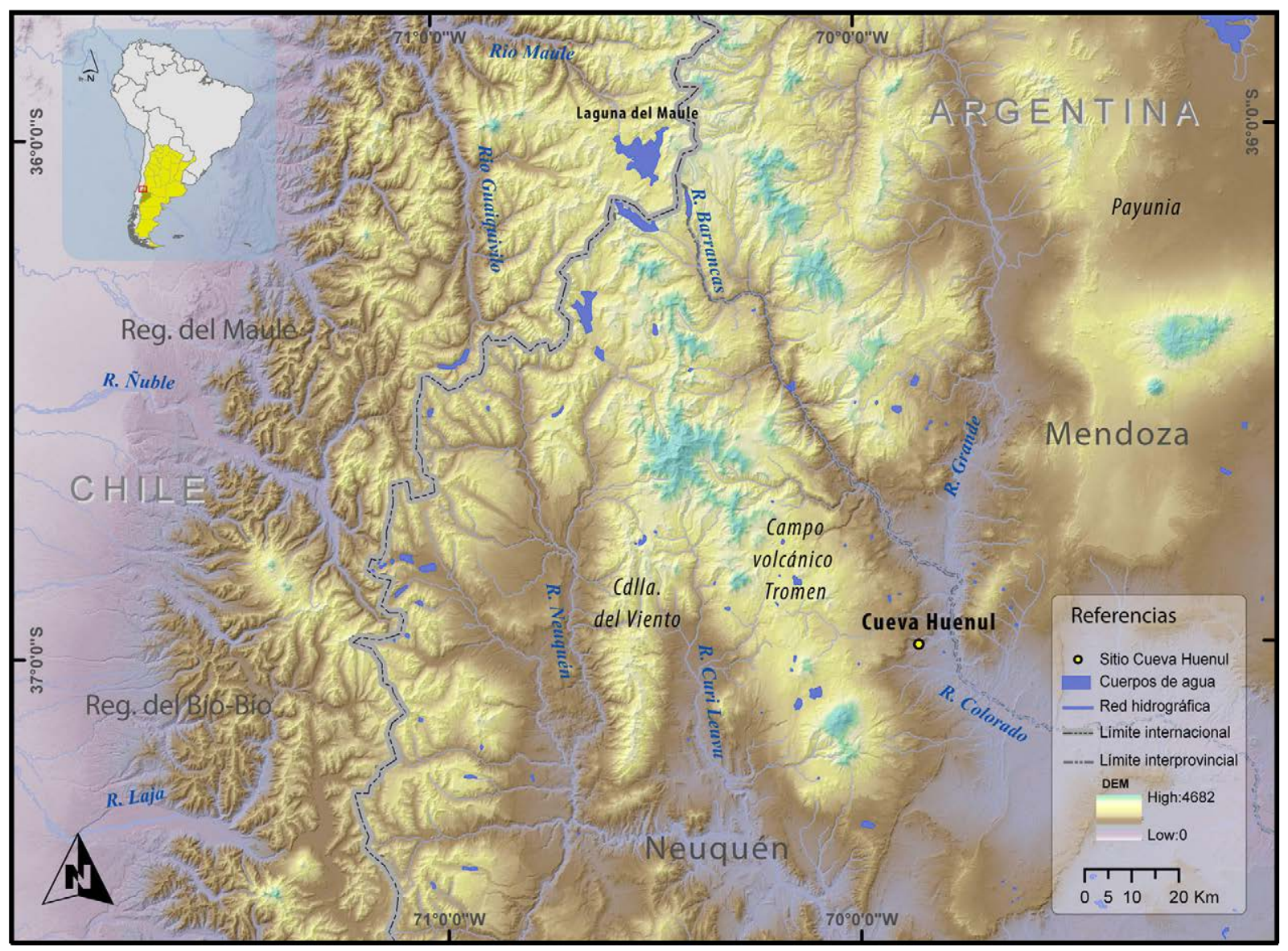

Figura 1. Ubicación del área de estudio y del sitio $\mathrm{CH} 1$.

de prospecciones y excavaciones sistemáticas (Llano y Barberena, 2013; Rughini et al., 2020, ver también Llano et al., en prensa). Finalmente, para generalizar el alcance de las observaciones realizadas en escala de sitio, se discute e integra la información obtenida en este estudio con aquella disponible a escala regional.

\section{Área de estudio}

La región de estudio se ubica en el extremo noroeste de Patagonia, en el norte de la provincia del Neuquén (departamento Pehuenches, localidad Barrancas-Buta Ranquil) (Figura 1). Fitogeográficamente, la unidad espacial definida por nuestra prospección arqueológica incluye el ecotono entre las comunidades del Monte, Patagonia y Altoandina (Páez, Quintana y Pérez, 2004; ver detalles en Rughini et al., 2020). Una de las características principales del área de estudio es la variabilidad ecológica vinculada al importante gradiente topográfico en distancias acotadas, ya que en aproximadamente $30 \mathrm{~km}$ se transita entre 700 y $2.000 \mathrm{~m}$ s.n.m. En una escala regional, el sitio $\mathrm{CH} 1$ ocupa un lugar destacado en la arqueología del norte de Neuquén, al proveer las evidencias más tempranas para el poblamiento humano del noroeste de Patagonia (Barberena, 2015). Jorge Fernández y colaboradores iniciaron las investigaciones en el sitio en el año 1978. Actualmente, el paradero de los materiales arqueológicos recuperados en esas primeras excavaciones es desconocido, y la información contextual no está publicada (aunque, ver fecha en Cordero, Lanzelotti y Panarello, 2002). En el marco del desarrollo de recientes investigaciones y perspectivas de análisis, el sitio fue vuelto a excavar con el propósito 
de generar nuevos aportes a la arqueología de la región (Barberena et al., 2015). CH1 se ubica en los espacios de baja altitud del Monte (1.000 m s.n.m.), caracterizados por un clima árido y cálido y de topografía leve que facilita la circulación en todo el ciclo anual (Barberena, 2013; Rughini et al., 2020) (Figura 1).

A nivel de la estructura de los recursos líticos (sensu Ericson, 1984), se destaca la amplia disponibilidad local de nódulos de obsidiana (con corteza) de la fuente Cerro Huenul en asociación con depósitos de ignimbritas de la Formación Tilhué (Barberena et al., 2011, 2019; Fernández et al., 2017). Desde un punto de vista arqueológico, Cerro Huenul constituye una fuente secundaria (sensu Nami, 1992), de disponibilidad inmediata (sensu Civalero y Franco, 2003) y de fácil acceso en la región, con materias primas de excelente calidad para la talla (sensu Aragón y Franco, 1997). Asimismo, en cercanías a la cuenca de los ríos Barrancas y Colorado se hallaron nódulos de obsidiana pertenecientes al tipo químico Laguna del Maule 2 -Río Barrancas- (Barberena et al., 2019), y hasta el momento se ha registrado la disponibilidad inmediatamente local de otras materias primas presentes en el registro arqueológico, como basalto y sílices.

La cavidad que alberga el sitio $\mathrm{CH} 1$ es de grandes dimensiones $-18 \times 35 \mathrm{~m}-\mathrm{y}$ fue originada por procesos erosivos de carácter hídrico (Figura 2). Se realizaron dos excavaciones localizadas en diferentes sectores interiores del reparo. En este trabajo presentamos los resultados del análisis de los materiales provenientes de las cuadrículas A1 ( $2 \times 1 \mathrm{~m}$; profundidad: $1,4 \mathrm{~m}$; volumen: $\left.2,8 \mathrm{~m}^{3}\right)$ y B1 $(1 \times 1 \mathrm{~m}$; profundidad: $0,95 \mathrm{~m}$; volumen: $0,95 \mathrm{~m}^{3}$ ) (Figura 3).

En la cuadrícula A1 se han identificado ocho unidades lito-estratigráficas que fueron agrupadas en cuatro componentes temporales. En trabajos previos se ha presentado en detalle el marco crono-estratigráfico de $\mathrm{CH} 1$ (cf. Barberena, 2014, 2015). Las unidades estratigráficas VIII a V están fechadas en su piso y techo por edades de $13844 \pm 75$ AP (AA85722, sobre coprolito a $100-110 \mathrm{~cm}$ ) y $11841 \pm 56$ (AA85720, sobre coprolito a 50-60 cm). Estas unidades constituyen el Componente 1, que corresponde al Pleistoceno final y no presentaría evidencias arqueológicas in situ, registrándose sólo ocupación de megafauna del taxón Pilosa (Barberena et al., 2015).

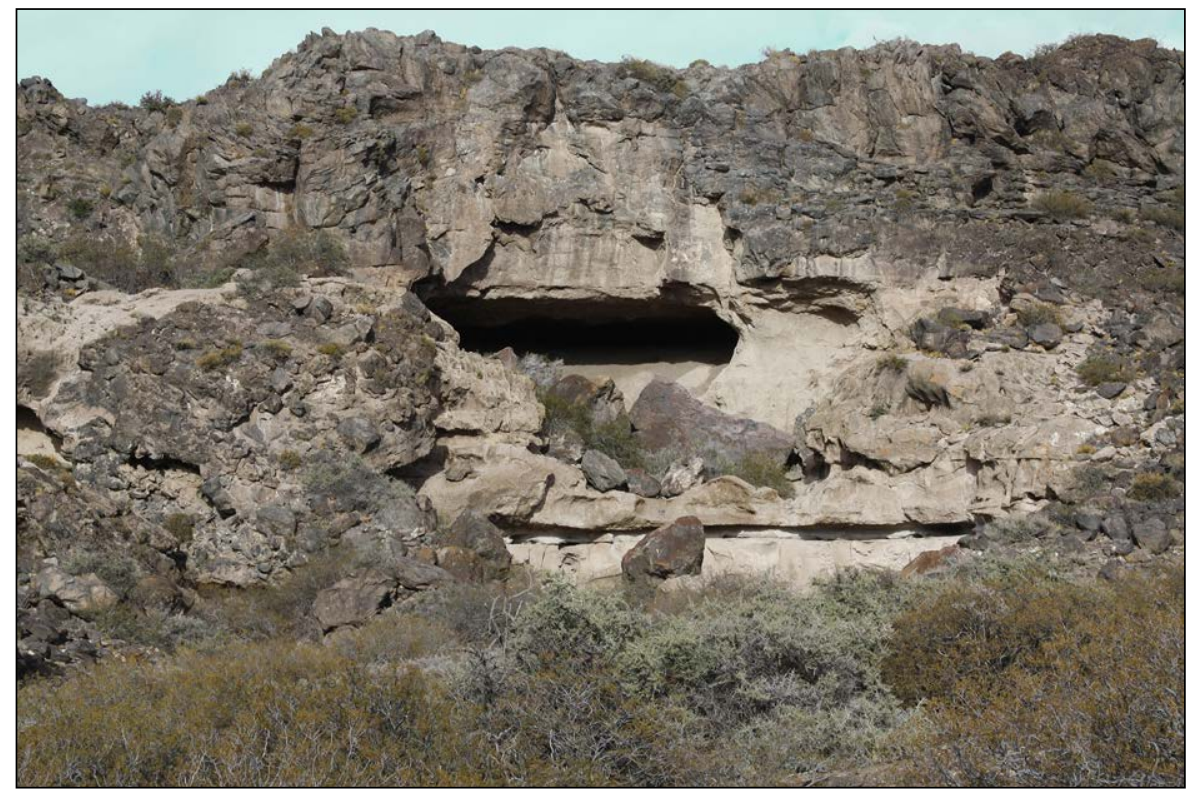

Figura 2. Vista frontal de $\mathrm{CH} 1$. 


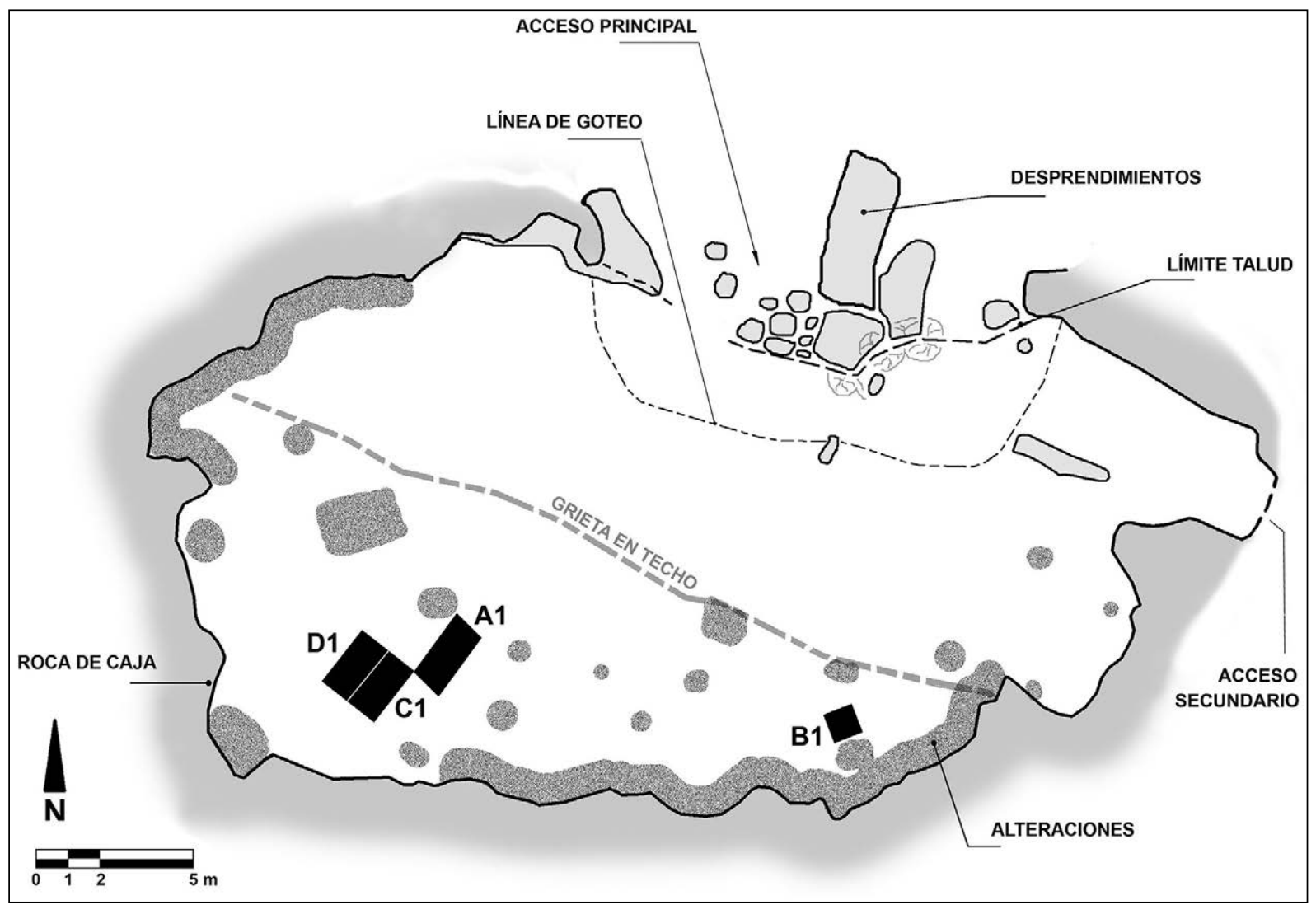

Figura 3. Planta del sitio $\mathrm{CH} 1$.

La unidad lito-estratigráfica IV corresponde al Componente temporal 2, asociado al Holoceno temprano y presenta cuatro fechados con edades de $10155 \pm 98 \mathrm{AP}$ (AA99106, sobre hueso de Lama guanicoe a 50-60 cm), $9531 \pm 39$ (AA85718, sobre carbón a 55-57 cm), $9295 \pm 90$ (AA99105, sobre hueso de Lama guanicoe a 40-50 cm) y $9375 \pm 91$ (AA99104, sobre hueso de Lama guanicoe a 40-50 cm) (Barberena, 2013; Barberena et al., 2015). En este componente se registran las primeras ocupaciones humanas del sitio.

Una estructura de pozo antrópico (estructura G, cuadrícula D1) rellena de material vegetal asignado a Senna aphylla y teñida con ocre rojo, fue fechada en $4786 \pm 46$ (AA102575, a 20-30 cm). Esta estructura y un fragmento de cáscara de huevo de Rheidae recuperado entre el material vegetal, son las únicas evidencias estratigráficas asignadas al Holoceno medio y definen al Componente 3. Por último, el Componente 4 abarca las unidades estratigráficas III-I, y está fechado en $1590 \pm 46$ AP (AA99103, sobre hueso de Lama guanicoe a $30-40 \mathrm{~cm}$ ), $1416 \pm 37$ AP (AA85721, sobre gramíneas a 20-30 cm) y $373 \pm 43 \mathrm{AP}$ (AA99102, en hueso de Lama guanicoe a 10-20 cm). La cuadrícula B1 produjo dos fechados: $1753 \pm 47$ AP (AA99110, sobre hueso de Lama guanicoe a 50-60 cm) y $1269 \pm 46$ AP (AA99109, sobre hueso de Lama guanicoe a 30 $-20 \mathrm{~cm})$.

En síntesis, la secuencia de $\mathrm{CH} 1$ es fuertemente discontinua y su segmento con aporte antrópico exhibe una baja potencia sedimentaria $(\mathrm{ca} .60 \mathrm{~cm}$ ). Sin embargo, la integridad vertical de los depósitos, evidenciada por la distribución de las fechas disponibles (Barberena, 2013), ofrece dos sólidas ventanas temporales ubicadas en los extremos del proceso de poblamiento regional, para la comparación de tasas y patrones de descarte de artefactos líticos. 


\section{Metodología}

Se realizaron excavaciones en dos sectores diferentes de la cueva (cuadrícula A1 y B1), mediante niveles artificiales de extracción de $10 \mathrm{~cm}$ de potencia, los cuales se enumeraron a partir de 1 desde la superficie hasta la base de la excavación. Las edades radiocarbónicas fueron obtenidas mediante AMS en el laboratorio National Science Foundation AMS Laboratory, University of Arizona (Estados Unidos). Las fechas se calibraron con el programa OxCal 4.2 (Bronk Ramsey, 2009), utilizando la curva de SH13 (Hogg et al., 2013). Además, se emplearon dos desvíos estándar, con la excepción de aquellos casos en que, debido a la morfología de la curva de calibración, un solo desvío estándar otorga una probabilidad que es $\geq 0,95$ de integrar la edad real del evento datado.

El análisis tecno-morfológico se desarrolló utilizando la propuesta de Aschero $(1975,1983)$ y las modificaciones incorporadas por Aschero y Hocsman (2004). Para la definición del tamaño de las piezas se utilizó una grilla milimetrada con intervalos de $5 \mathrm{~mm}$ de lado (sensu Franco, 2002). Sin embargo, en la fracción más pequeña de los desechos, representada por piezas menores o iguales a $5 \mathrm{~mm}$, correspondiente a lo que consideramos como microdesechos (sensu Sherwood, 2001), sólo se registró el tipo de materia prima y el porcentaje de reserva de corteza en la cara dorsal. Particularmente, su tratamiento se realiza separadamente ya que, debido a su pequeño tamaño, estos materiales generan un sobredimensionamiento de la muestra. En el futuro se prevén estudios adicionales de esa fracción de los desechos con la asistencia de instrumental óptico.

Las materias primas fueron identificadas macroscópicamente a través de la comparación con muestras de mano previamente analizadas petrográficamente por medio de cortes delgados. Además, se realizaron análisis geoquímicos sobre artefactos de obsidiana recuperados en $\mathrm{CH} 1$ utilizando el método de Fluorescencia de Rayos X (Shackley, 2005).

Por último, para el cálculo de las tasas de descarte se consideró la totalidad de los artefactos (desechos, microdesechos, núcleos y artefactos formatizados) por componente y por cuadrícula. A nivel temporal, se consideró el lapso entre las medianas de las fechas calibradas disponibles para base y techo de cada componente. Para el Componente 2 se excluye la edad considerada outlier (11841 $\pm 56 \mathrm{AP})$.

\section{Resultados}

El total de artefactos líticos analizados es de 5.688. De ellos, 1.473 proceden de la cuadrícula A1 y 4.215 de la cuadrícula B1 (Tabla 1). Los resultados geoquímicos para 123 artefactos del sitio han sido publicados recientemente (Barberena et al., 2011; Fernández et al., 2017) (Figura 4). Esos análisis sobre artefactos de $\mathrm{CH} 1$ mostraron un amplio predominio de la obsidiana Cerro Huenul $(n=116 ; 94,3 \%)$, disponible en el entorno inmediato del sitio $\mathrm{CH} 1$. En menor medida se registró la presencia de obsidiana de las fuentes Laguna del Maule 2-Río Barrancas ( $n=6 ; 4,9 \%$ ), que también es local aunque está disponible a una distancia mínima de $4 \mathrm{~km}$ en el río Colorado y Laguna del Maule 1-Laguna Negra $(n=1 ; 0,8 \%)$, que no es local y está disponible en las tierras altas cercanas al límite internacional, a una distancia mínima lineal de ca. $80 \mathrm{~km}$ de CH1 (Barberena et al., 2019).

La obsidiana es la materia prima más frecuente en todas las clases artefactuales de la secuencia de $\mathrm{CH} 1(85,1 \%)$ y registra su mayor aporte en el componente tardío (Tabla 2). Luego le siguen las rocas silíceas $(13,4 \%)$, el basalto $(1,3 \%$ ) y, en un muy bajo porcentaje, una materia prima indeterminada (Tabla 2). 


\begin{tabular}{|c|c|c|c|c|c|c|c|c|c|}
\hline Cuad. & Comp. & Niveles & Total & Microdesechos & Des. de talla & $\begin{array}{c}\text { Artefactos } \\
\text { formatizados }\end{array}$ & Núcleos & FNRC & Ecof. \\
\hline \multirow{9}{*}{$\mathrm{A} 1$} & \multirow{3}{*}{4} & 1 & 14 & $5(0,5 \%)$ & $8(1,8 \%)$ & $1(14,2 \%)$ & - & - & - \\
\hline & & 2 & 329 & $217(21,1 \%)$ & $106(25 \%)$ & $3(42,8 \%)$ & $1(12,5 \%)$ & $2(66,6 \%)$ & - \\
\hline & & 3 & 771 & $595(58 \%)$ & $168(40 \%)$ & $2(28,7 \%)$ & $5(62,5 \%)$ & $1(33,33 \%)$ & - \\
\hline & \multirow{2}{*}{2} & 4 & 240 & $143(14 \%)$ & $96(22 \%)$ & $1(14,2 \%)$ & - & - & - \\
\hline & & 5 & 100 & $63(6,1 \%)$ & $36(8,4 \%)$ & - & $1(12,5 \%)$ & - & - \\
\hline & \multirow{3}{*}{1} & 6 & 7 & - & $6(1,4 \%)$ & - & $1(12,5 \%)$ & - & - \\
\hline & & 7 & 10 & $3(0,3 \%)$ & $7(1,6 \%)$ & - & - & - & - \\
\hline & & 8 & 2 & $1(0,09 \%)$ & $1(0,2 \%)$ & - & - & - & - \\
\hline & Total & & 1.473 & $1.027(100 \%)$ & $428(100 \%)$ & $7(100 \%)$ & $8(100 \%)$ & $3(100 \%)$ & - \\
\hline \multirow{9}{*}{ B1 } & \multirow{8}{*}{4} & 1 & 411 & $370(15,6 \%)$ & $38(2,13 \%)$ & $1(5 \%)$ & $1(3,33 \%)$ & $1(25 \%)$ & - \\
\hline & & 2 & 720 & $358(15,11 \%)$ & $353(19,8 \%)$ & - & $6(20 \%)$ & $1(25 \%)$ & $2(15,4 \%)$ \\
\hline & & 3 & 1.010 & $565(23,8 \%)$ & $427(24 \%)$ & $12(60 \%)$ & $3(10 \%)$ & $1(25 \%)$ & $2(15,4 \%)$ \\
\hline & & 4 & 445 & $279(11,8 \%)$ & $160(8,9 \%)$ & - & $6(20 \%)$ & - & - \\
\hline & & 5 & 659 & $372(15,7 \%)$ & $274(15,4 \%)$ & $5(25 \%)$ & $6(20 \%)$ & $1(25 \%)$ & $1(7,7 \%)$ \\
\hline & & 6 & 482 & $240(10,1 \%)$ & $234(13,1 \%)$ & - & $7(23,3 \%)$ & - & $1(7,7 \%)$ \\
\hline & & 7 & 388 & $163(6,8 \%)$ & $220(12,3 \%)$ & $2(10 \%)$ & $1(3,33 \%)$ & - & $2(15,4 \%)$ \\
\hline & & 8 & 100 & $21(0,88 \%)$ & $74(4,1 \%)$ & - & - & - & $5(38,5 \%)$ \\
\hline & Total & & 4.215 & $2.368(100 \%)$ & $1.780(100 \%)$ & $20(100 \%)$ & $30(100 \%)$ & $4(100 \%)$ & $13(100 \%)$ \\
\hline
\end{tabular}

Tabla 1. Frecuencia de clases artefactuales por cuadrículas en CH1. Referencias: Cuad.: cuadrícula; Comp.: Componente; Des.: desechos; FNRC: filo natural con rastros complementarios; Ecof.: ecofactos.

\begin{tabular}{|c|c|c|c|c|c|}
\hline Cuadrícula & \multicolumn{4}{|c|}{ A1 } & B1 \\
\hline Materia prima & Componente 1 & Componente 2 & Componente 4 & Total por MP & Componente 4 (total por MP) \\
\hline Obsidiana & $15(79 \%)$ & $307(90,3 \%)$ & $932(83,7 \%)$ & $1.254(85,1 \%$ & $4.021(95,4 \%)$ \\
Rocas silíceas & $2(10,5 \%$ & $18(4,4 \%)$ & $181(16,2 \%)$ & $198(13,4 \%)$ & $172(4,1 \%)$ \\
Basalto & $2(10,5 \%)$ & $15(5,3 \%)$ & - & $20(1,3 \%$ & $10(0,2 \%)$ \\
Indeterminada & - & - & $1(0,1 \%)$ & $1(0,1 \%)$ & $12(0,3 \%)$ \\
\hline Total & $\mathbf{1 9 ( 1 0 0 \% )}$ & $\mathbf{3 4 0 ( 1 0 0 \% )}$ & $\mathbf{1 . 1 1 4}(\mathbf{1 0 0} \%)$ & $\mathbf{1 . 4 7 3}(\mathbf{1 0 0} \%)$ & $\mathbf{4 . 2 1 5 ( 1 0 0 \% )}$ \\
\hline
\end{tabular}

Tabla 2. Frecuencia de materias primas por componente temporal y cuadrícula (A1 y B1) de CH1. Referencias: MP: Materia Prima.

\section{Análisis tecno-morfológico de la cuadrícula A1}

En esta cuadrícula se identificaron tres componentes crono-estratigráficos: el Componente 1 (paleontológico, Pleistoceno final) y los componentes arqueológicos 2 (Holoceno temprano) y 4 (Holoceno tardío). Por su posición cronológica y contexto sedimentario, se considera que los artefactos del Componente 1 habrían migrado verticalmente por procesos post-depositacionales desde niveles estratigráficos superiores (Barberena et al., 2015). 
De los 1.473 artefactos recuperados en esta cuadrícula, 1.027 son microdesechos $(69,72 \%)$ y constituyen la categoría más representada de la muestra (Tabla 1). Su frecuencia siempre supera a la de las restantes categorías artefactuales, excepto en el Componente 1, y es mayoritaria en el componente tardío (Figura 4). La materia prima más representada en los microdesechos es la obsidiana con el $86,6 \%(n=890)$; ninguno de ellos presenta reserva de corteza.

A continuación, se presenta el análisis de los artefactos líticos (mayores a $5 \mathrm{~mm}$ de lado) en la cuadrícula A1 agrupados por componente. Como ya mencionamos, el análisis subsiguiente no incluye a los microdesechos.

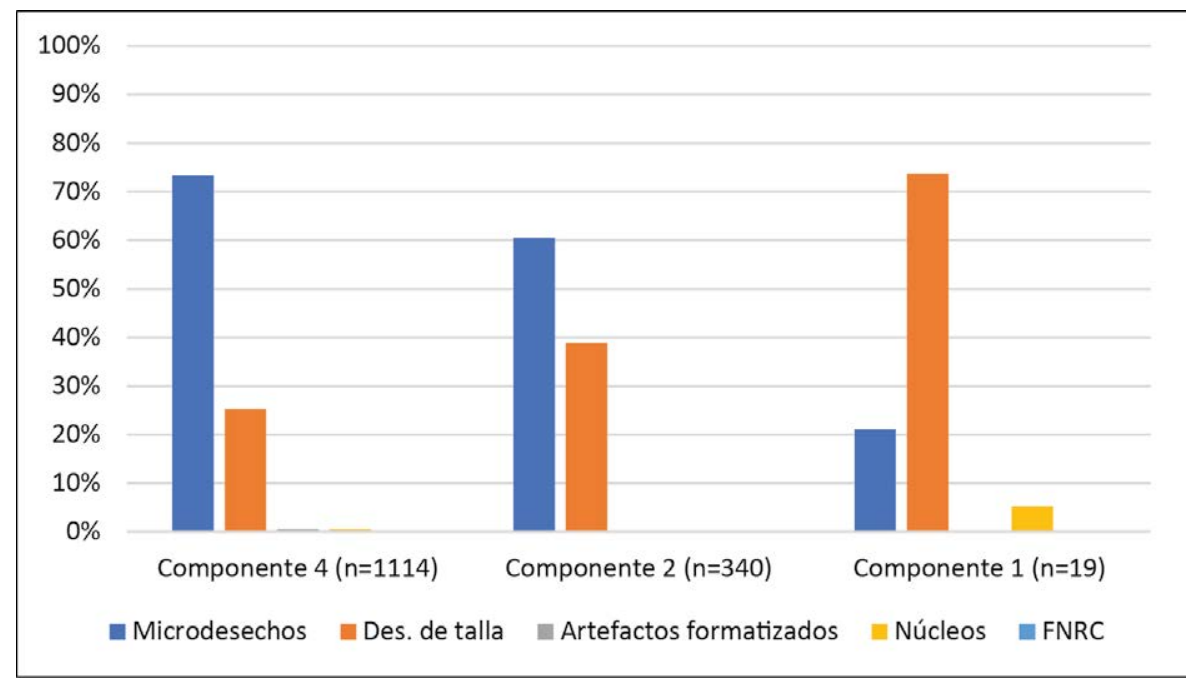

Figura 4. Frecuencia relativa de clases artefactuales por componente de la cuadrícula A1. Componente 1: niveles 8, 7 y 6; Componente 2: niveles 5 y 4; Componente 4: niveles 3, 2 y 1. Referencias: Des.: Desechos, FNRC: Filo natural con rastros complementarios.

\section{Componente 1: Pleistoceno final}

Este componente fue datado entre 16700-13600 años cal. AP y su matriz sedimentaria es de origen paleontológico (Barberena et al., 2015). Se registraron 15 artefactos de pequeñas dimensiones que, como ya mencionamos, habrían migrado desde niveles superiores adyacentes. La clase artefactual más abundante corresponde a la de los desechos de talla ( $n=14 ; 93,33 \%)$ (Tabla 1$)$ y un núcleo completa la muestra.

La obsidiana $(78,6 \%)$ es predominante entre los desechos de talla, tanto en lascas externas como internas (Tabla 3). El basalto y las rocas silíceas ( $14,3 \%$ y $7,1 \%$, respectivamente) prevalecen entre las lascas internas (Tabla 3). La reserva de corteza es más frecuente en los desechos de obsidiana. Aproximadamente el $57 \%$ de los desechos de talla están enteros y son pequeños (tamaños 10 y $15 \mathrm{~mm}$ de la grilla). El único núcleo registrado en este componente es bipolar, de roca silícea y está entero (Tabla 1). Su tamaño es de $40 \mathrm{~mm}$, posee el $50 \%$ de reserva de corteza y una única extracción. Por otra parte, consideramos que la ausencia de microdesechos en estos niveles puede deberse, en parte, a la baja actividad humana asociada con los mismos (Barberena et al., 2015).

\section{Componente 2: Holoceno temprano}

Los niveles artificiales de extracción 4 y 5 correspondientes a este componente fueron datados en el Holoceno temprano mediante cuatro fechas ${ }^{14} \mathrm{C}$ entre 12000 y 10300 años 


\begin{tabular}{|c|c|c|c|c|c|c|c|c|}
\hline \multirow{2}{*}{ Desecho de talla } & \multicolumn{3}{|c|}{ Componente 1 } & \multicolumn{3}{c|}{ Componente 2 } & \multicolumn{3}{c|}{ Componente 4 } \\
\cline { 2 - 8 } & Obs. & RS & Bas. & Obs. & RS & Bas. & Obs. & RS \\
\hline Lasca primaria & 6 & - & - & 9 & 1 & 1 & 24 & 1 \\
Lasca secundaria & 1 & - & - & 7 & 1 & - & 11 & 2 \\
Lasca con dorso natural & 1 & - & - & 4 & 1 & - & 6 & - \\
Lasca angular & 2 & - & 1 & 30 & 1 & 4 & 74 & 13 \\
Lasca indeterminada & - & 1 & 1 & 23 & 1 & 3 & 50 & 17 \\
Desecho indiferenciado & 1 & - & - & 7 & 1 & 2 & 28 & 7 \\
Lasca de arista & - & - & - & 11 & - & 1 & 13 & 5 \\
Lasca plana & - & - & - & 15 & 4 & 3 & 22 & 3 \\
Lasca de adelgazamiento bifacial & - & - & - & - & - & 1 & 1 & - \\
Hoja & - & - & - & 1 & - & - & - & - \\
Lasca de reactivación & - & - & - & - & - & - & - & 3 \\
Desecho Bipolar & - & - & - & - & - & - & 1 & 1 \\
\hline Total & $\mathbf{1 1}$ & $\mathbf{1}$ & $\mathbf{2}$ & $\mathbf{1 0 7}$ & $\mathbf{1 0}$ & $\mathbf{1 5}$ & $\mathbf{2 3 0}$ & $\mathbf{5 2}$ \\
\hline
\end{tabular}

Tabla 3. Frecuencia de tipos de desechos de talla de la cuadrícula A1 por materia prima. Referencias: Obs.: obsidiana; RS: roca silícea; Bas.: basalto.

cal AP (Barberena et al., 2015). La muestra de este componente asciende a 134 piezas (sin contabilizar los microdesechos) (Tabla 1). Los desechos de talla representan casi la totalidad del conjunto $(n=132 ; 98,5 \%)$, entre los cuales la obsidiana es la materia prima más frecuente $(n=107 ; 81 \%)$. Completan la muestra un artefacto formatizado indeterminado y un núcleo.

Entre los desechos de talla, las lascas internas $(n=108 ; 81,8 \%)$ son las más representadas, en obsidiana $(n=87 ; 80,5 \%)$, basalto $(n=14 ; 13 \%)$ y roca silícea $(n=7$; $6,5 \%)$; mientras que el $70 \%$ de ellas $(n=92)$ carece de reserva de corteza (Tabla 3$)$. Las lascas externas, por su parte, registran bajos porcentajes $(n=24 ; 18,2 \%)$ y se presentan mayormente sobre obsidiana $(n=20 ; 83,33 \%$ ) (Tabla 3$)$. El $62 \%$ de los desechos de talla $(n=82)$ posee un tamaño de $10 \mathrm{~mm}$, el $34 \%(n=45)$ se encuentra entre 15 y 25 $\mathrm{mm}$, y sólo el $3 \%(n=5)$ está comprendido entre los 30 y $45 \mathrm{~mm}$.

El $81 \%(n=109)$ del conjunto es de obsidiana y el resto es de rocas silíceas y basalto. De 36 artefactos de obsidiana que fueron analizados mediante XRF, 35 fueron asignados a la fuente Cerro Huenul y uno a Laguna del Maule 2-Río Barrancas, siendo ambas fuentes locales (Fernández et al., 2017).

La mayoría de los talones son lisos y naturales y los talones preparados que indicarían estadios más avanzados de la talla (i.e. puntiformes, facetados y filiformes) están escasamente representados (Barros, Martínez y Gutiérrez, 2014; Bradbury y Carr, 1995, 2014; Espinosa, 1995; Sullivan y Rozen, 1985, entre otros) (Tabla 4). En las lascas de obsidiana, los talones más representados son los lisos, seguidos en menor frecuencia por los talones naturales. En las lascas de basalto ocurre algo similar, mientras que en las de rocas silíceas predominan los naturales (Tabla 4).

El $40 \%(n=53)$ de los desechos de talla está fragmentado. La obsidiana presenta un índice de fragmentación del 0,95 mientras que el basalto se encuentra en el 0,66 y la roca silícea en 1. 


\begin{tabular}{|c|c|c|c|c|c|c|c|c|}
\hline Materia Prima & Liso & Nat. & Estall. & Died. & Puntif. & Facet. & Filif. & Total \\
\hline Obsidiana & $45(59,2 \%)$ & $13(17,1 \%)$ & $6(7,9 \%)$ & $6(7,9 \%)$ & $4(5,3 \%)$ & $1(1,3 \%)$ & $1(1,3 \%)$ & $76(100 \%)$ \\
Roca silícea & - & $5(83,3 \%)$ & $1(16,6 \%)$ & - & - & - & - & $6(100 \%)$ \\
Basalto & $6(66,6 \%)$ & - & $3(3,3 \%)$ & - & - & - & - & $9(100 \%)$ \\
\hline Total & $\mathbf{5 1}(\mathbf{5 6} \%)$ & $\mathbf{1 8 ( 1 9 , 8 \% )}$ & $\mathbf{1 0 ( 1 0 , 9 \% )}$ & $\mathbf{6 ( 6 , 6 \% )}$ & $\mathbf{4 ( 4 , 4 \% )}$ & $\mathbf{1 ( 1 , 1 \% )}$ & $\mathbf{1 ( 1 , 1 \% )}$ & $\mathbf{9 1 ( 1 0 0 \% )}$ \\
\hline
\end{tabular}

Tabla 4. Frecuencia de tipo de talones en el Componente 2 de la cuadrícula A1. Referencias: Nat: Naturales; Died: Diedro; Facet: Facetado; Filif: Filiforme; Puntif: Puntiforme; Estall: Estallado.

Los niveles correspondientes a este componente sólo proveyeron un artefacto formatizado de filo no diferenciado sobre obsidiana y sin reserva de corteza. Este se encuentra fracturado y posee un tamaño de $10 \mathrm{~mm}$. Por último, en este componente se recuperó un núcleo de lascados aislados (Tabla 3). Es de obsidiana y posee un $25 \%$ de reserva de corteza.

\section{Componente 4: Holoceno tardío}

Este componente está vinculado al período comprendido entre 1500-400 años cal. AP (Barberena et al., 2015). El total de artefactos es de 297 (sin microdesechos). Al igual que en los niveles anteriores, los desechos de talla dominan el conjunto $(94,9 \% ; n=282)$.

La materia prima predominante entre los desechos de talla $(n=282)$ es la obsidiana, que representa el $81,6 \%$ de la muestra $(n=230)$ (Tabla 3 ). Las rocas silíceas están representadas con el $18,4 \%(n=52)$; no se registran desechos de basalto. Las lascas internas $(n=238 ; 84,4 \%)$ prevalecen por sobre las externas $(n=44 ; 15,6 \%)$. Estas últimas están escasamente representadas en las rocas silíceas. Las lascas de reactivación están presentes únicamente sobre rocas silíceas y habrían sido producidas por reactivación de un filo bifacial (Tabla 3). Esto sugiere la representación de diferentes estadios de reducción sobre esa materia prima en el sitio.

La reserva de corteza está ausente en el 70,1\% $(n=199)$ de los desechos de talla. Estos datos sugieren una mayor presencia de etapas intermedias y finales de talla por sobre las iniciales de la secuencia de reducción lítica. La mayoría de los desechos de talla de rocas silíceas no posee reserva de corteza $(n=43 ; 83 \%)$. En el caso de la obsidiana, si bien la mayoría de las piezas tampoco presenta corteza, la frecuencia es menor ( $\mathrm{n}=$ $156 ; 68 \%$ ). En parte, esta mayor presencia de corteza en la obsidiana podría deberse a que los nódulos son de disponibilidad local y abundante en $\mathrm{CH}$ 1, lo que habría facilitado su aprovisionamiento. El pequeño tamaño de los nódulos de obsidiana Huenul también contribuiría a reforzar este patrón.

Los talones registrados $(n=165)$ en su mayoría son lisos $(n=78 ; 42,3 \%)$, naturales $(n=$ $26 ; 16 \%$ y diedros $(n=21 ; 12,7 \%)$. En obsidiana los que más prevalecen son lisos $(n=$ $65 ; 47,1 \%)$, naturales $(n=24 ; 17,4 \%)$, diedros $(n=17 ; 12,3 \%)$, facetados $(n=14 ; 10,1 \%)$, puntiformes $(n=8 ; 5,6 \%)$, estallados $(n=8 ; 5,6 \%)$ y filiformes $(n=2 ; 1,4 \%)$; mientras que en rocas silíceas son lisos $(n=13 ; 48,1 \%)$, diedros $(n=4 ; 14,8 \%)$, facetados $(n=3 ; 11,1 \%)$, naturales $(n=2 ; 7,4 \%)$, filiformes $(n=2 ; 7,4 \%)$, puntiformes $(n=2 ; 7,4 \%)$ y estallado $(n=1$; $3,7 \%$ ). Más de la mitad de los desechos de talla están enteros $(n=163 ; 57,3 \%)$. Al evaluar el estado de los mismos de acuerdo con la materia prima, se observa que el índice de fragmentación de la obsidiana $(0,96)$ es superior al registrado en rocas silíceas $(0,79)$.

La mayoría ( $n=6 ; 85,7 \%)$ de los artefactos formatizados recuperados en la cuadrícula A1 procede de este componente (Tabla 1). Están confeccionados sobre obsidiana, a 
excepción de un instrumento sobre roca silícea. El grupo tipológico más frecuente es la punta de proyectil $(n=2 ; 22,2 \%)$. Una de las puntas es un fragmento basal-ápice cuya morfología no ha sido establecida, mientras que la otra está confeccionada sobre roca silícea y tiene una morfología triangular apedunculada. La serie técnica está compuesta por retoques extendidos sobre toda la pieza, su tamaño es de $35 \mathrm{~mm}$ (grilla de tamaño) y está reactivada. Los restantes grupos tipológicos están, en cada caso, representados por un ejemplar (chopping tool, preforma de posible instrumento bifacial, artefacto formatizado indeterminado y retoque en bisel oblicuo, en adelante RBO). Gran parte de los instrumentos están fragmentados $(n=4 ; 66,6 \%)$, con excepción de una punta de proyectil y un RBO, y el $66,6 \%(n=4)$ presenta reserva de corteza. Sobre la base de estas características se puede sostener que, a excepción de las puntas de proyectil, en general los instrumentos no presentan una formatización intensa ni exhiben filos que indiquen una gran inversión de trabajo en su manufactura. Las formas base de los artefactos formatizados que pudieron ser registradas son: una lasca primaria, una lasca con dorso natural, una lasca angular, un artefacto formatizado indeterminado y un núcleo. Los talones de las formas base identificados son dos naturales y uno estallado. Por último, se identificaron tres filos naturales con rastros complementarios $(0,26 \%)$, todos ellos sobre obsidiana (Tabla 1 ).

De los ocho núcleos recuperados en esta cuadrícula, seis proceden de los niveles tardíos (Componente 4) (Tabla 1 y 5). Entre ellos se registraron cinco núcleos de lascados aislados sobre obsidiana y uno bipolar sobre roca silícea. A excepción de una pieza, todos los núcleos poseen reserva de corteza y, en su mayoría, están enteros. Sus tamaños oscilan entre 15 y $40 \mathrm{~mm}$ (grilla de tamaño), presentando muy pocas extracciones, a excepción del núcleo bipolar sobre roca silícea que presenta el mayor número mínimo de extracciones $(n=6)$. Los tipos de plataforma de percusión registrados en los núcleos son: cortical-natural $(n=3 ; 50 \%)$, lisa-preparada $(n=2 ; 33,3 \%)$ $y$, en un solo caso, estallada $(16,6 \%)$. Las terminaciones de los negativos de lascados son: aguda $(n=3 ; 50 \%)$, quebrada $(n=2 ; 33,3 \%)$ y en charnela $(n=1 ; 16,6 \%)$. Esta última está vinculada a errores de talla o fractura directa (sensu Weitzel y Colombo, 2006), lo que podría indicar un exceso de energía o su mala aplicación (Tabla 5).

\section{Análisis tecno-morfológico de la cuadrícula B1}

El total de artefactos líticos recuperados en esta cuadrícula es de 4.215 (Tabla 1). Los microdesechos representan el $56,2 \%$ del conjunto $(n=2.368)$. El $97,3 \%$ de estos

\begin{tabular}{|c|c|c|c|c|c|c|c|c|c|}
\hline Componente & $\begin{array}{c}\text { Tam. } \\
(\mathbf{m m})\end{array}$ & $\begin{array}{c}\mathbf{L} \\
(\mathbf{m m})\end{array}$ & $\begin{array}{c}\mathbf{A} \\
(\mathbf{m m})\end{array}$ & $\begin{array}{c}\mathbf{E} \\
(\mathbf{m m})\end{array}$ & $\begin{array}{c}\text { Vol. } \\
(\mathbf{m m})\end{array}$ & Materia prima & Forma Base & $\begin{array}{c}\text { Cant. mín. } \\
\text { de extracc. }\end{array}$ & $\begin{array}{c}\text { Neg. Ls. } \\
(\mathbf{m m})\end{array}$ \\
\hline 1 & 40 & 49 & 22 & 13 & 14.014 & Roca silícea & Nódulo & 1 & 21 \\
\hline 2 & 30 & 27 & 21 & 12 & 6.804 & Obsidiana & Indet. & 2 & 26 \\
\hline & 25 & 28 & 21 & 10 & 5.880 & Obsidiana & Indet. & 1 & 27 \\
& 40 & 42 & 29 & 19 & 23.142 & Obsidiana & Nódulo & 1 & 19 \\
& 30 & 30 & 23 & 12 & 8.280 & Obsidiana & Nódulo & 1 & 24 \\
& 15 & 17 & 11 & 2 & 374 & Obsidiana & Indet. & 1 & 20 \\
& 40 & 49 & 22 & 13 & 14.014 & Obsidiana & Nódulo & 1 & 21 \\
& 35 & 36 & 28 & 15 & 15.120 & Roca silícea & Indet. & 6 & 34 \\
\hline
\end{tabular}

Tabla 5. Núcleos recuperados en la cuadrícula A1. Referencias: Tam: Tamaño; L: Largo; A: Ancho; E: Espesor; Vol: Volumen (mm3); Indet.: Indeterminado; Cant. mín. extracc.: Cantidad mínima de extracciones; Neg. Ls.: dimensión máxima del negativo de lascado más grande. 
es de obsidiana y el 2,5\% de roca silícea. Los restantes microdesechos aparecen en basalto y materias primas indeterminadas con el $0,1 \%$. En esta categoría artefactual la reserva de corteza está ausente. Luego, siguen en abundancia los desechos de talla $(n=1.780)$, artefactos formatizados $(n=20)$, ecofactos $(n=13)$, filos naturales con rastros complementarios $(n=4)$ y completan la muestra núcleos $(n=27)$ y nódulos probados $(n=3)$.

El $95,4 \%(n=4.021)$ de los artefactos está manufacturado sobre obsidiana. Las rocas silíceas $(n=172 ; 4,08 \%)$, el basalto $(n=12 ; 0,23 \%)$ y las rocas indeterminadas $(n=12 ; 0,28 \%)$ completan el conjunto. A continuación, se presenta el análisis tecnomorfológico de los artefactos líticos (mayores a $5 \mathrm{~mm}$ de lado) recuperados en la cuadrícula B1.

\section{Componente 4: Holoceno tardío}

Este componente abarca la totalidad de la secuencia de la cuadrícula B1, que corresponde a ocho niveles artificiales de extracción (Barberena et al., 2015). El total (excluyendo los microdesechos) es de 1.847 artefactos.

Los desechos de talla son la clase artefactual más frecuente $(n=1.780 ; 42,2 \%)$ (Tabla 1 y 6). En cuanto a las materias primas, la obsidiana es la más representada en los desechos $(n=1.654 ; 92,9 \%)$. Entre estos, las rocas silíceas están poco representadas $(n=109 ; 6,1 \%)$, seguidas por el basalto $(n=9 ; 0,5 \%)$ y materias primas indeterminadas $(n=8 ; 0,4 \%)$.

Las lascas internas son las más abundantes en todas las materias primas. Sin embargo, las lascas externas en rocas silíceas y basalto $(n=12 ; 3,1 \%, n=1 ; 0,2 \%$, respectivamente) son más escasas en comparación con lo registrado entre los desechos de obsidiana $(n=375 ; 95,9 \%)$. Esto podría indicar que los artefactos sobre rocas silíceas y basalto ingresaron al sitio descortezados, o bien, serían una consecuencia del mayor tamaño de los nódulos en estas dos últimas materias primas, en comparación con aquel registrado en los rodados de obsidiana (Tabla 6).

\begin{tabular}{|c|c|c|c|c|}
\hline \multicolumn{5}{|c|}{ Componente 4 } \\
\hline Desecho de talla & Obsidiana & Roca Silícea & Basalto & Indet. \\
\hline Lasca Primaria & 177 & 5 & 1 & 3 \\
Lasca Secundaria & 107 & 26 & - & - \\
Lasca con dorso natural & 50 & 18 & - & - \\
Lasca Angular & 314 & 185 & 12 & 1 \\
Lasca de arista & 23 & 9 & - & - \\
Lasca Plana & 64 & 23 & 4 & 3 \\
Lasca Adelgazamiento & 4 & - & - & - \\
Lasca Reactivación & - & - & - & - \\
Microlasca & 279 & 41 & 3 & 2 \\
Lasca Indeterminada & 120 & 32 & 2 & - \\
Desecho Bipolar & 9 & - & - & - \\
Desecho Indeterminado & 207 & 11 & 5 & - \\
\hline
\end{tabular}

Tabla 6. Frecuencia de desechos de talla por materias primas en el Componente 4 de la cuadrícula B1. Referencias: Indet.: indeterminada. 
En el caso de la obsidiana la frecuencia de piezas sin corteza es elevada, aunque probablemente haya sido obtenida en la localidad. La mayoría de los desechos de talla no posee reserva de corteza en su cara dorsal $(n=1.186 ; 66,6 \%)$; cabe destacar que las piezas sin corteza son más frecuentes entre las rocas silíceas y el basalto ( $\mathrm{n}$ $=88 ; 80,7 \%$ y $n=6 ; 88,9 \%$, respectivamente).

Los talones registrados con mayor frecuencia son lisos y naturales (Tabla 7). Los talones diedros, estallados y puntiformes se asocian a una talla de estadios más avanzados (Barros et al., 2014; Bradbury y Carr, 1995, 2014; Espinosa, 1995; Nami, 1991; Sullivan y Rozen, 1985, entre otros). Los desechos de talla de obsidiana presentan todos los tipos de talones; por su parte, en los de rocas silíceas los tipos de talones más representados son lisos, seguidos por naturales y diedros. En cambio, en los desechos de basalto se observa una mayor frecuencia de talones lisos y facetados que naturales y diedros (Tabla 7).

El $64,5 \%$ de los desechos de talla están enteros $(n=1.148)$. Cabe destacar que en obsidiana y rocas silíceas el índice de fragmentación es similar $(0,56$ y 0,53 respectivamente), mientras que en basalto es más alto $(0,75)$. La distribución de los tamaños de los desechos de talla se concentra entre los 10 y $30 \mathrm{~mm}$ (98,5\%).

Se recuperó un total de 20 instrumentos, todos confeccionados sobre obsidiana (Tabla 1). Según los estudios geoquímicos realizados, la materia prima de una de las puntas de proyectil -que además presenta pigmento adherido en su superficie-corresponde al tipo Laguna del Maule 2, cuya fuente más cercana se localiza sobre el río Barrancas, a aproximadamente $5 \mathrm{~km}$ de $\mathrm{CH} 1$ (Fernández et al., 2017). Los instrumentos enteros son los más frecuentes $(n=13 ; 65 \%)$. La presencia de reserva de corteza en los instrumentos ocurre en el $45 \%$ de los casos $(n=9)$, lo que sugiere el aprovechamiento de lascas externas o lascas internas con remanente de corteza como formas base para formatizar los instrumentos. Los tamaños de las piezas enteras oscilan entre 25 y $35 \mathrm{~mm}$ y en un solo caso el tamaño es de $45 \mathrm{~mm}$. Si consideramos que la obsidiana ha sido la materia prima empleada en la manufactura de los artefactos formatizados registrados en $\mathrm{CH} 1$, cabe plantear que la frecuente existencia de remanentes de corteza en estas piezas esté asociada al pequeño tamaño de los nódulos explotados. En este sentido, sólo unas pocas formas base de los mayores tamaños posibles serían extraíbles desde los pequeños nódulos disponibles y ellas corresponderían a las instancias iniciales de reducción.

Entre las puntas de proyectil $(n=6)$, el subgrupo tipológico representado es la punta de forma triangular apedunculada $(n=6 ; 25 \%)$. En general, todas poseen adelgazamiento bifacial, base cóncava, lados convexos y tamaños que oscilan entre los 25 y $30 \mathrm{~mm}$. Al comparar los tamaños representados en los desechos de talla enteros (10 a $30 \mathrm{~mm})$ y las dimensiones alcanzadas por las puntas de proyectil descartadas en el sitio ( 25 y $30 \mathrm{~mm}$ ), es posible proponer que aquellas lascas de mayor tamaño producidas en

\begin{tabular}{|c|c|c|c|c|c|c|c|c|}
\hline Materia Prima & Liso & Nat. & Died. & Estall. & Puntif. & Facet. & Filif. & Total \\
\hline Obsidiana & $308(36 \%)$ & $259(30,3 \%)$ & $170(19,9 \%)$ & $49(5,7 \%)$ & $45(5,2 \%)$ & $20(2,3 \%)$ & $4(0,5 \%)$ & $855(100 \%)$ \\
Roca silícea & $27(55,1 \%)$ & $9(18,4 \%)$ & $9(18,4 \%)$ & - & - & $4(8,2 z \%)$ & - & $49(100 \%)$ \\
Basalto & $5(55,5 \%)$ & $1(11,1 \%)$ & $1(11,1 \%)$ & - & - & $2(22,2 \%)$ & - & $9(100 \%)$ \\
Indeterminada & $1(20 \%$ & $3(60 \%)$ & $1(60 \%)$ & - & - & - & - & $5(100 \%)$ \\
\hline Total & $\mathbf{3 4 1}(\mathbf{3 7 , 1} \%)$ & $\mathbf{2 7 2}(\mathbf{2 9 , 6 \% )}$ & $\mathbf{1 8 1}(\mathbf{1 9 , 7} \%)$ & $\mathbf{4 9} \mathbf{( 5 , 3 \% )}$ & $\mathbf{4 5 ( 4 , 9 \% )}$ & $\mathbf{2 6 ( 2 , 8 \% )}$ & $\mathbf{4 ( 0 , 4 \% )}$ & $\mathbf{9 1 8 ( 1 0 0 \% )}$ \\
\hline
\end{tabular}

Tabla 7. Frecuencia de tipos de talones en la cuadrícula B1. Referencias: Nat: Naturales; Died: Diedro; Facet: Facetado; Filif: Filiforme; Puntif: Puntiforme; Estall: Estallado 
el sitio pudieron haber sido seleccionadas como soportes para formatizar las puntas de proyectil o los demás instrumentos. La mitad de las puntas de proyectil están fragmentadas en la base o el ápice. La serie técnica predominante de las puntas de proyectil es el retoque extendido y microretoque marginal y no se observaron evidencias de reactivación. Posiblemente tres de estas piezas tengan restos de algún pegamento (mastic) cuya composición aún resta analizar. Las preformas recuperadas $(n=4 ; 20 \%$ ) son, en dos casos, de punta de proyectil y, en otros dos, de artefactos formatizados bifaciales no diferenciados. Su serie técnica es retalla extendida y retoque marginal.

Al igual que lo observado en la cuadrícula A1, el resto de los artefactos formatizados en B1 no presenta evidencias de una intensa formatización ni de reactivación, a excepción de uno de los cortantes. Los raspadores y los RBO $(n=3 ; 15 \%$, en cada caso) son los instrumentos unifaciales más frecuentes. Los raspadores son de filo corto, sus ángulos medidos varían entre $65^{\circ}$ y $95^{\circ}$ y sus tamaños oscilan entre 25 y $35 \mathrm{~mm}$. El grupo tipológico siguiente en frecuencia es el cortante $(n=2 ; 10 \%)$, con ángulos medidos entre $45^{\circ}$ y $55^{\circ}$ y tamaños entre 25 y $30 \mathrm{~mm}$. Un cuchillo $(20 \mathrm{~mm})$ y un artefacto formatizado indeterminado $(45 \mathrm{~mm})$ completan la muestra. Sus ángulos medidos son de $35^{\circ}$ y $40^{\circ}$, respectivamente.

En B1 se registraron 27 núcleos (Tabla 8) y tres nódulos probados (Nami, 1986) entre los cuales la obsidiana es la materia prima predominante $(n=28 ; 93,3 \%)$. La mayoría de los núcleos está entera $(n=26 ; 96 \%)$. Los nódulos probados presentan reserva de corteza y sus tamaños oscilan entre $25 \mathrm{~mm}(n=1)$ y $36 \mathrm{~mm}(n=2)$. Los tipos de núcleos registrados son bipolares $(n=14 ; 52 \%)$ y de lascados aislados $(n=13 ; 48 \%)$. Las formas base utilizadas fueron nódulos y artefactos indeterminados. En promedio, los núcleos miden 30,9 por 24,6 por $12,3 \mathrm{~mm}$. En el caso de los núcleos bipolares, su tamaño se encuentra, predominantemente, entre $30-35 \mathrm{~mm}(n=9)$ y $20-25 \mathrm{~mm}(\mathrm{n}=3)$. Los dos bipolares restantes poseen tamaños de $15 \mathrm{~mm}(n=1)$ y $40 \mathrm{~mm}(n=1)$, siendo ambos de obsidiana y presentan la mayor cantidad de extracciones (hasta 5). En cambio, los tamaños de los núcleos de lascados aislados se encuentran entre $25 \mathrm{~mm}(n=3), 30$ $\mathrm{mm}(\mathrm{n}=4)$ y $35 \mathrm{~mm}(\mathrm{n}=6)$, lo que indica el aprovechamiento de nódulos con pequeños tamaños. Cabe destacar que aproximadamente el $86 \%$ de las piezas posee tamaños entre 25 y $35 \mathrm{~mm}$, similar al tamaño de los nódulos registrados en las inmediaciones del sitio (Barberena et al., 2011). La mayoría de los núcleos $(n=25 ; 92,6 \%)$ presenta reserva de corteza de 25 a 75\%, lo que podría indicar una baja intensidad de explotación de los núcleos debido a la proximidad de las fuentes (Paulides, 2006). Sin embargo, no es posible descartar que este patrón derive de las limitaciones impuestas por el tamaño pequeño de los nódulos predominantes para la extracción de formas base de dimensiones adecuadas (Bradbury y Carr, 1995).

Por último, se recuperaron cuatro filos naturales con rastros complementarios en B1 ( $n$ $=4 ; 0,1 \%$ ). Los mismos tienen como formas base una lasca indeterminada y tres lascas angulares, con talones cortical, estallado y facetado. Se ha detectado la presencia de un borde con rastros en cada pieza, todos ellos con ángulos de $45^{\circ}$.

\section{Discusión y conclusiones}

\section{Estrategias tecnológicas}

Como se ha mencionado, el sitio $\mathrm{CH} 1$ cuenta con varias dataciones radiocarbónicas que abarcan desde la transición Pleistoceno-Holoceno hasta momentos tardíos del Holoceno (Barberena, 2015). Si no se considera la fecha que podría ser anómala (rango 


\begin{tabular}{|c|c|c|c|c|c|c|c|c|c|}
\hline \multicolumn{10}{|c|}{ Componente 4} \\
\hline $\begin{array}{l}\text { Tipo de } \\
\text { núcleo }\end{array}$ & M-P & Cort. & Tam. & $L(\mathrm{~mm})$ & $A(\mathrm{~mm})$ & $E(\mathrm{~mm})$ & Vol. $\left(\mathrm{mm}^{3}\right)$ & $\begin{array}{l}\text { Cant. mín. } \\
\text { de extracc. }\end{array}$ & Neg. Ls. \\
\hline Bipolar & Obs. & $75 \%$ & 30 & 30 & 24 & 16 & 11.520 & 2 & 34 \\
\hline Bipolar & Obs. & $50 \%$ & 30 & 36 & 27 & 11 & 10.692 & 3 & 23 \\
\hline Bipolar & R. Sil. & $0 \%$ & 25 & 33 & 16 & 5 & 2.640 & 5 & 20 \\
\hline Bipolar & Obs. & $50 \%$ & 20 & 20 & 22 & 9 & 3.960 & 2 & 13 \\
\hline Bipolar & Obs. & $25 \%$ & 30 & 28 & 23 & 12 & 7.728 & 3 & 31 \\
\hline Bipolar & Obs. & $75 \%$ & 40 & 38 & 32 & 18 & 21.888 & 1 & 14 \\
\hline Bipolar & Obs. & $75 \%$ & 30 & 38 & 20 & 12 & 9.120 & 3 & 22 \\
\hline Bipolar & Obs. & $25 \%$ & 30 & 32 & 27 & 10 & 8.640 & 3 & 30 \\
\hline Bipolar & Obs. & $50 \%$ & 30 & 30 & 32 & 12 & 11.520 & 1 & 30 \\
\hline Bipolar & Obs. & $25 \%$ & 15 & 16 & 15 & 10 & 2.400 & 5 & 17 \\
\hline Bipolar & Obs. & $0 \%$ & 35 & 41 & 25 & 13 & 13.325 & 1 & 19 \\
\hline Bipolar & Obs. & $50 \%$ & 35 & 34 & 26 & 9 & 7.956 & 2 & 21 \\
\hline Bipolar & Obs. & $50 \%$ & 35 & 33 & 25 & 15 & 12.375 & 2 & 23 \\
\hline Bipolar & Obs. & $25 \%$ & 20 & 14 & 17 & 11 & 2.618 & 1 & 11 \\
\hline Ls. aisl. & Obs. & $25 \%$ & 25 & 30 & 19 & 11 & 6.270 & 2 & 30 \\
\hline Ls. aisl. & Obs. & $50 \%$ & 35 & 31 & 29 & 14 & 12.586 & 1 & 18 \\
\hline Ls. aisl. & Obs. & $50 \%$ & 30 & 27 & 29 & 10 & 7.830 & 1 & 17 \\
\hline Ls. aisl. & R. Sil. & $50 \%$ & 35 & 40 & 21 & 12 & 10.080 & 1 & 29 \\
\hline Ls. aisl. & Obs. & $50 \%$ & 25 & 26 & 15 & 10 & 3.900 & 1 & 35 \\
\hline Ls. aisl. & Obs. & $50 \%$ & 35 & 44 & 30 & 19 & 25.080 & 3 & 20 \\
\hline Ls. aisl. & Obs. & $25 \%$ & 35 & 29 & 22 & 16 & 10.208 & 1 & 32 \\
\hline Ls. aisl. & Obs. & $50 \%$ & 30 & 32 & 18 & 11 & 6.336 & 1 & 21 \\
\hline Ls. aisl. & Obs. & $25 \%$ & 30 & 29 & 30 & 8 & 6.960 & 2 & 25 \\
\hline Ls. aisl. & Obs. & $75 \%$ & 35 & 33 & 32 & 18 & 19.008 & 1 & 21 \\
\hline Ls. aisl. & Obs. & $50 \%$ & 25 & 24 & 22 & 10 & 5.280 & 1 & 22 \\
\hline Ls. aisl. & Obs. & $25 \%$ & 35 & 28 & 30 & 9 & 7.560 & 2 & 18 \\
\hline Ls. aisl. & Obs. & $75 \%$ & 30 & 30 & 30 & 21 & 18.900 & 2 & 30 \\
\hline
\end{tabular}

Tabla 8. Núcleos de la cuadrícula B1. Referencias: Tam: Tamaño; L: Largo; A: Ancho; E: Espesor; Vol: Volumen (mm3); R. Sil.: Roca silícea; M-P: Materia Prima; Cant. mín. extracc.: Cantidad mínima de extracciones; Neg. Ls.: dimensión máxima del negativo de lascado más grande.

calibrado entre 11294-12032 años AP), las primeras ocupaciones humanas defendibles ocurren entre 11000-10200 años cal. AP en el Componente 2. Durante este período las actividades de producción lítica desarrolladas en el sitio habrían estado vinculadas a las etapas intermedias de la secuencia de reducción y/o manufactura, principalmente sobre obsidiana. Esto es coherente con el predominio de lascas internas por sobre externas y el pequeño tamaño de las piezas representado (tamaño $10 \mathrm{~mm}$ ). La virtual ausencia de artefactos formatizados para este momento es compatible con el bajo porcentaje registrado de talones preparados (Tabla 4). En conjunto, estas evidencias sugieren que las actividades tecnológicas en estos primeros momentos de la ocupación en $\mathrm{CH} 1$ giraron en torno a la extracción de formas base sobre núcleos previamente descortezados o cuyas etapas intermedias y finales de la secuencia de reducción y/o manufactura se realizaron en otro lugar. En este contexto, consideramos que los grupos humanos que habitaron el sitio durante el Holoceno temprano habrían implementado estrategias de equipamiento de los individuos (Binford, 1978, 1979; Kuhn, 1992, 2004), mediante las cuales pudieron haber trasladado los artefactos extraídos como parte del equipo personal, ya sea como instrumentos confeccionados o formas base. Esto es 
compatible con contextos de alta movilidad como los que habrían sido característicos del poblamiento de la región durante el Holoceno temprano (Barberena et al., 2015; Borrero, 2005; Crivelli Montero et al., 1996).

El uso temprano de las obsidianas Cerro Huenul y Laguna del Maule 2-Río Barrancas, ambas de carácter local, contribuye a plantear que los grupos cazadores-recolectores ya poseían un adecuado conocimiento de los recursos líticos locales del área de estudio desde al menos el inicio del Holoceno. Esto es coherente con el uso expeditivo registrado sobre la obsidiana, probablemente debido a su amplia disponibilidad y fácil acceso (Nelson, 1991). Los desechos de talla internos, sin reserva de corteza, se observan sobre rocas silíceas (no disponibles en forma inmediata, sensu Civalero y Franco, 2003) y sobre basalto, los cuales habrían ingresado a $\mathrm{CH} 1$ en forma de núcleos y/o artefactos formatizados. Para estos momentos tempranos, el sitio presenta una baja intensidad ocupacional humana y el escaso descarte de instrumentos es congruente con ocupaciones humanas breves y muy esporádicas. Lo mismo puede inferirse a partir de los conjuntos zooarqueológicos, arqueobotánicos y el contexto estratigráfico en general (Barberena et al., 2015; Llano et al., 2019).

El siguiente bloque de ocupaciones humanas examinado en $\mathrm{CH} 1$ se desarrolla durante los últimos 1500 años cal (Componente 4). Las principales actividades de talla registradas durante este período continúan vinculadas a etapas avanzadas de manufactura, como lo indica la mayor frecuencia de lascas internas, aunque los talones preparados presentan poca frecuencia. La obsidiana sigue siendo la materia prima predominante y con ella se confeccionó la mayoría de los instrumentos. Se observa una disminución en el aporte de las restantes materias primas en el conjunto artefactual. Hemos registrado que la explotación de la obsidiana se da desde comienzos del Holoceno temprano en la localidad Barrancas-Buta Ranquil. A diferencia de ese período, en el componente tardío son más frecuentes las tareas de formatización y/o mantenimiento y de recambio de instrumentos formales (sensu Andrefsky, 1994), como las puntas de proyectil. Este tipo de artefactos formatizados requiere de mayor inversión de tiempo y esfuerzo tecnológico e implica estrategias de conservación (sensu Binford, 1979; Franco, 2004; Nelson, 1991). Los instrumentos informales (sensu Andresfsky, 1994) de obsidiana, de uso y descarte inmediato, son abundantes en el sitio, están enteros, poseen reserva de corteza, son de tamaño pequeño y tienen sus filos embotados, sin evidencias de mantenimiento. La baja estandarización y la clase técnica (sensu Aschero y Hocsman, 2004), predominantemente registrada en estos instrumentos (retoque marginal), muestra poca inversión de trabajo y sugiere el empleo de estrategias tecnológicas expeditivas (Nelson, 1991). Los núcleos de menor tamaño poseen evidencias de una mayor intensidad de explotación. Los núcleos de obsidiana han sido explotados a través de la talla bipolar. Como proponen Flegenheimer, Bayón y González Bonaveri (1995), la aplicación de esta técnica podría relacionarse con el aprovisionamiento de los nódulos de obsidiana de tamaño pequeño ( $\leq 50 \mathrm{~mm}$ ) disponibles en las inmediaciones del sitio.

En el marco del proyecto regional, se llevó a cabo una experiencia de talla sobre obsidiana (Borrazzo, Weitzel y Ceraso, 2020). Para la misma se utilizaron ocho nódulos de obsidiana de la fuente Cerro Huenul obtenida en el entorno de $\mathrm{CH}$. Sus resultados indicaron que también durante los estadios iniciales de talla y de extracción de formas base se producen lascas pequeñas que presentan atributos comparables a aquellos de las etapas avanzadas de talla y/o de formatización. Estas observaciones experimentales plantean que una parte importante de los microdesechos, usualmente asociados a etapas finales del proceso de reducción lítica (Barros et al., 2014; Bradbury y Carr, 1995, 2014; Espinosa, 1995; Nami, 1991; Sullivan y Rozen, 1985; entre otros), podría en realidad corresponder a distintas etapas del proceso de talla de obsidiana. Sin embargo, la covariación entre la frecuencia de microdesechos y artefactos de 
pequeño tamaño en ambas secuencias estratigráficas sugiere que, en términos generales, el aumento de la fracción artefactual pequeña resultaría de un incremento en la frecuencia de actividades de talla en $\mathrm{CH} 1$, especialmente de las etapas finales. Esta observación, junto con los datos experimentales, nos permite proponer que la presencia de microdesechos en ambas cuadrículas puede considerarse un indicador confiable del desarrollo de actividades de talla in situ de las etapas intermedias y finales.

\section{Historia ocupacional}

Se observa que la señal de uso humano, manifestada en la frecuencia de depositación artefactual, es similar en ambos componentes, como lo corrobora la tasa de depositación del Componente 2 (de 1,06 artefactos/año) y del Componente 4 (0,93/ año) de la cuadrícula A1. En cambio, en el Componente 4 de B1 la tasa de descarte de artefactos es mayor ( 3,82 artefacto/año), lo que podría estar indicando una diferencia en cuanto a la intensidad ocupacional intrasitio. Este uso más recurrente de $\mathrm{CH} 1$ hacia el Holoceno tardío tiene lugar en un contexto regional marcado por un crecimiento demográfico, la incorporación efectiva en los territorios humanos de áreas disponibles, pero no ocupadas previamente en forma sistemática y el uso de nuevas tecnologías como la cerámica, el arco y flecha, y la demarcación sistemática del paisaje mediante el arte rupestre, incluidos los espacios estacionales de altura de los Andes (Barberena, 2013; Hajduk et al., 2011; Neme y Gil, 2008; Romero Villanueva et al., 2020; Salgán, 2015). Sin embargo, desde la perspectiva de la organización de la tecnología lítica no se observaron cambios profundos en las estrategias implementadas entre el Holoceno temprano y tardío en A1, vinculadas principalmente a estadías de corta duración y a una relativamente baja inversión tecnológica. En cambio, los principales contrastes están dados por la tasa de depositación de artefactos líticos más que por el modo en que se organizó la tecnología (cf. Bettinger, Madsen y Elston, 1994), específicamente en los componentes tardíos de A1 y de B1. Esto ocurre en un contexto estratigráfico caracterizado por la presencia de prolongados hiatos ocupacionales, que abarcan la mayor parte del Holoceno. Este hallazgo resulta muy informativo sobre el modo en que $\mathrm{CH} 1$, que es un sitio excepcional por sus características morfológicas y por las manifestaciones rupestres y el arte mobiliar que presenta (Romero Villanueva, 2020; Romero Villanueva y Barberena, 2017; Romero Villanueva et al., 2020), es incorporado en los circuitos de movilidad humana. Aunque hay aspectos clave a nivel de la conducta humana que se modificaron a través del tiempo, tal como la intensidad en la demarcación rupestre del sitio (Barberena et al., 2017; Romero Villanueva, 2020; Romero Villanueva y Barberena, 2017), las actividades de talla lítica no se habrían modificado cualitativamente. Consideramos que esto puede explicarse por una combinación de aspectos locacionales (Borrero, 1982; Vita-Finzi, 1978). Por una parte, el emplazamiento de $\mathrm{CH} 1$ en un área de cantera-taller de la obsidiana del grupo Cerro Huenul habría condicionado el registro de instancias semejantes en el proceso de reducción lítica en la ocupación del sitio a través del tiempo, independientemente hasta cierto punto- de la instancia demográfica regional y, por otra parte, aunque se requiere una mayor información paleoecológica local, el emplazamiento no inmediato (ca. $4 \mathrm{~km}$ ) de $\mathrm{CH} 1$ a fuentes de agua permanentes, también puede haber conducido al desarrollo de ocupaciones de baja intensidad a través del tiempo. Es coincidente con esta interpretación la virtual ausencia de cerámica en $\mathrm{CH} 1$ y su entorno inmediato, en contraposición con su presencia en el sitio Cueva Yagui localizado a $6 \mathrm{~km}$ de $\mathrm{CH} 1(\mathrm{n}=$ 62, Rughini et al., 2020) y emplazado sobre la cuenca del arroyo Buta Có. Además, ese sitio presenta una tasa y modo de descarte de artefactos líticos diferentes. No obstante, cabe señalar que $\mathrm{CH} 1$ es el sitio con el número más elevado de motivos rupestres en la región ( $n=4.446$, Romero Villanueva, 2019). En este sentido, consideramos que es muy valioso integrar información sobre la historia ocupacional de emplazamientos fijos en el paisaje que han sido seleccionados sistemáticamente a través del tiempo 
para demarcar mediante arte rupestre. Resulta interesante comparar indicadores independientes de la historia ocupacional local como un acercamiento compatible con la escala temporal arqueológica a los modos de uso (Holdaway y Wandsnider, 2006).

\section{Conclusiones y perspectivas}

El presente trabajo representa un paso central en el proceso de análisis y publicación detallada del sitio Cueva Huenul 1, que ofrece evidencia clave para distintas instancias del poblamiento humano del noroeste de Patagonia. Esta información estratigráfica sobre patrones en la organización de la tecnología lítica será integrada con evidencias zooarqueológicas, arqueobotánicas y de representaciones rupestres, actualmente en proceso de estudio para Cueva Huenul 1, así como las de otros sitios de la región. De suma importancia será la articulación de estas tendencias temporales con la información espacial recientemente generada en el marco de un programa regional de arqueología distribucional (Rughini et al., 2020). Sobre esta base, se avanzará en la reconstrucción de las redes de interacción y movilidad humana entre distintos sectores biogeográficos de la región, así como con la vertiente occidental de la cordillera de los Andes.

\section{Agradecimientos}

Este trabajo fue financiado por los proyectos PICT 2014-0940 (dirigido por el Dr. Víctor A. Durán) y PICT 201-0062 (Agencia Nacional de Promoción de la Ciencia y la Tecnología). Agradecemos a las autoridades de las localidades Barrancas y Buta Ranquil (provincia del Neuquén), quienes nos han ayudado a través de los años y merecen un reconocimiento especial. A Claudia Della Negra, Carlos Cides y Pablo Azar (Subsecretaría de Cultura de la Provincia del Neuquén) por toda su colaboración. Reconocemos el apoyo de Guadalupe Romero Villanueva, M. Victoria Fernández, Carina Llano, Agustina Brera, Jimena Paiva y Agustín Castillo. Por último, queremos agradecer los aportes y sugerencias de los evaluadores que consolidaron este trabajo. 


\section{Referencias citadas}

»Andrefsky, W. (1994). Raw-material availability and the organization of technology. American Antiquity, 59(1), 21-34.

» Aragón, E. y Franco, N. V. (1997). Características de rocas para la talla por percusión y propiedades petrográficas. Anales del Instituto de la Patagonia, 25, 187-199.

»Aschero, C. (1975). Ensayo para una clasificación morfológica de artefactos líticos aplicados a estudios tipológicos comparativos. Informe al CONICET. Manuscrito inédito.

»Aschero, C. (1983). Ensayo para una clasificación morfológica de artefactos líticos aplicada a estudios tipológicos comparativos. Informe a CONICET. Revisión 1983. Manuscrito inédito.

»Aschero, C. y Hocsman, S. (2004). Revisando cuestiones tipológicas en torno a la clasificación de artefactos bifaciales. En A. Acosta, D. Loponte y M. Ramos (Eds.), Temas de arqueología. Análisis lítico (pp. 7-25). Luján: Universidad Nacional de Luján.

» Barberena, R. (2013). Biogeografía, competencia y demarcación simbólica del espacio: modelo arqueológico para el norte de Neuquén. Intersecciones en Antropología, 14, 367-381.

» Barberena, R. (2014). Discordancias y discontinuidades en Patagonia septentrional: Cronoestratigrafía de Cueva Huenul 1 (Neuquén, Argentina). En V. Cortegoso, V. Durán y A. Gasco (Eds.), Arqueología en ambientes de altura en Mendoza y San Juan (pp. 203-219). Mendoza: Editorial Universidad Nacional de Cuyo.

» Barberena, R. (2015). Cueva Huenul 1 archaeological site (Northwestern Patagonia, Argentina: Initial colonization and mid-Holocene demographic retraction. Latin American Antiquity, 26(3), 304-318. https://doi.org/10.7183/1045-6635.26.3.304

» Barberena, R., Borrazzo, K., Rughini, A., Romero Villanueva, G., Pompei, M. P., Llano, C., de Porras, M. E., Durán, V., Stern, C., Re, A., Estrella, D., Forasiepi, A., Fernández, F., Chidiak, M., Acuña L., Gasco, A. y Quiroga, M. N. (2015). Perspectivas arqueológicas para Patagonia septentrional: Sitio Cueva Huenul 1 (Provincia del Neuquén, Argentina). Magallania, 43(1), 1-27. http://dx.doi.org/10.4067/S0718-22442015000100009

» Barberena, R., Fernández, M. V., Rughini, A., Borrazzo, K., Garvey, R., Lucero, G., Della Negra, C., Romero Villanueva, G., Durán, V., Cortegoso, V., Giesso, M., Klesner, C., MacDonald, B. L. y Glascock, M. D. (2019). Deconstructing a Complex Obsidian 'Source-scape': A Geoarchaeological and Geochemical Approach in Northwestern Patagonia. Geoarchaeology, 34, 30-41. https://doi.org/10.1002/gea.21701

» Barberena, R., Hajduk, A., Gil, A. F, Neme, G. A., Durán, V., Glascock, M. D., Giesso, M., Borrazzo K., Pompei, M. P., Salgán, M. L., Cortegoso, V., Villlarosa, G. y Rughini, A. (2011). Obsidian in the south-central Andes: geological, geochemical, and archaeological assessment of north Patagonian Sources (Argentina). Quaternary International, 245(1), 25-36.

» Barberena, R., Romero Villanueva, G., Lucero, G., Fernández, M. V., Rughini, A. y Sosa, P. (2017). Espacios Internodales en Patagonia Septentrional: Biogeografía, Información y Mecanismos sociales de Interacción. Estudios Atacameños, 56, 57-75.

» Barros, M. P., Martínez, G. y Gutiérrez, M. A. (2014). Análisis de los materiales líticos del sitio Paso Otero 4 (partida de Necochea, Provincia de Buenas Aires). Avances en el conocimiento de las estrategias tecnológicas en el curso medio del río Quequén grande durante el Pleistoceno tardío-Holoceno. Relaciones de la Sociedad de Antropología, XXXIX, 119-144.

» Bettinger, R. L., Madsen, D. B. y Elston, R. G. (1994). Prehistoric Settlement Categories and Settlement Systems in the Alashan Desert of Inner Mongolia. Journal of Anthropological Archaeology, 13(1), 74-101.

» Binford, L. (1978). Dimensional analysis of behavior and site structure: Learning from an Eskimo hunting stand. American Antiquity, 43, 330-361. 
» Binford, L. (1979). Organization and Formation Processes: looking at curated technologies. Journal of Anthropological Research, 35, 255-273.

» Binford, L. (1980). Willow smoke and dog's tails: hunter and gatherers settlement systems and archaeological site formation. American Antiquity, 45, 4-20.

» Borrazzo, K., Weitzel, M. C. y Ceraso, A. (2020). Exploración experimental de los efectos del pisoteo sobre artefactos de obsidiana. Revista del Museo de Antropología, 13(1), 341-346. https://doi.org/10.31048/1852.4826.v13.n1.23826

» Borrero, L. A. (1982). Factores de localización de sitios arqueológicos en la región del curso inferior del río Limay. Trabajo presentado en la Primera Reunión Nacional de Ciencias del Hombre en Zonas Áridas. Mendoza, Argentina.

» Borrero, L. A. (2005). The Archaeology of the Patagonian Deserts: Hunter-Gathers in a Cold Desert. En P. Veth, M. Smith y P. Hiscock (Eds.), Desert Peoples. Archaeological Perspectives (pp. 142-158). Oxford: Blackwell.

» Borrero, L. A. (2016). Ambiguity and Debates on the Early Peopling of South America. PaleoAmerica, 2(1), 11-21.

» Bradbury, A. P. y Carr, P. J. (1995). Flake typologies ad alternative approaches: an experimental assessment. Lithic Technology, 20(2), 100-115.

»Bradbury, A. P. y Carr, P. J. (2014). Non-metric continuum-based flake analysis. Lithic Technology, 19(1), 20-38.

» Bronk Ramsey, C. (2009). Bayesian analysis of radiocarbon dates. Radiocarbon, 51(1), 337-360.

» Campbell, R., Moya Cañoles, F., y Gutiérrez, R. (2020). Quien busca, encuentra. Arte rupestre en el sur de Chile: evaluación, perspectivas y preguntas. Boletín del Museo Chileno de Arte Precolombino, 25(1), 247-69.

» Civalero, M. T. y Franco, N. V. (2003). Early human occupations in western Santa Cruz province, Southernmost South America. Quaternary International, 109-110, 77-86.

» Cordero, R., Lanzelotti, H. y Panarello, S. (2002). INGEIS RadiocarbonLaboratory Dates IV. Radiocarbon, 44(1), 181-193.

» Crivelli Montero, E. A., Pardiñas, U. F. J., Fernández, M. M., Bogazzi, M., Chauvin, A., Fernández, V. M. y Lezcano, M. J. (1996). La cueva Epullán Grande (Provincia del Neuquén, Argentina). Informe de avance. Praehistoria, 2, 185-265.

» Ericson, J. E. (1984). Toward the analysis of lithic production system. En J. E. Ericson y B. Purdy (Eds.), Prehistoric Quarries and Lithic Production (pp. 1-9). Cambridge: Cambridge University Press.

»Espinosa, S. (1995). Dr. Scholl y Monsieur Fleur: De talones y bulbos. Cuadernos del Instituto Nacional de Antropología y Pensamiento Latinoamericano, 16, 315-327.

» Fernández, M. V., Barberena, R., Rughini, A., Giesso, M., Cortegoso, V., Durán, V., Romero Villanueva, G., Borrazzo, K., Lucero, G., Garvey, R., MacDonald, B. L. y Glascock, M. D. (2017). Obsidian geochemistry, geoarchaeology, and lithic technology in northwestern Patagonia (Argentina). Journal of Archeological Science: Reports, 13, 372-381.

» Flegenheimer, N., Bayón, C. y González Bonaveri, M. (1995). Técnica simple, comportamientos complejos: la talla bipolar en la arqueología bonaerense. Relaciones de la Sociedad Argentina de Antropología, XX, 81-110.

»Franco, N. (2002). Estrategias de utilización de recursos líticos en la cuenca superior del río Santa Cruz (Argentina). (Tesis Doctoral inédita), Universidad de Buenos Aires, Argentina.

»Franco, N. (2004). La organización tecnológica y el uso de las escalas espaciales amplias. El caso del sur y oeste del Lago Argentina. En A. Acosta, D. Loponte y M. Ramos (Eds.), Temas de Análisis lítico (pp. 101-144). Luján: Universidad de Luján.

» Hajduk, A., Albornoz, A. y Lezcano, M. J. (2011). Espacio, cultura y tiempo: el corredor bioceánico desde la perspectiva arqueológica. En P. Navarro Floria y W. Delrío (Eds.), Cultura y espacio. Araucanía-Norpatagonia (pp. 262-292). Bariloche: Universidad Nacional de Río Negro. 
»Hogg, A. G., Hua, Q., Blackwell, P. G., Niu, M., Buck, C. E., Guilderson, T. P., Heaton, T. J., Palmer, J. G., Reimer, P. J., Reimer, R. W., Turney, C. S. M. y Zimmerman, S. R. H. (2013). SHCAL 13 Southern Hemisphere Calibration, 0-50,000 Years CAL BP. Radiocarbon, 55(4), 1889-1903.

» Holdaway, S. J. y Wandsnider, L. A. (2006). Temporal Scales and Archaeological Landscapes from the Eastern Desert of Australia and Intermontane North America. En G. Lock y B. Molyneaux (Eds.), Confronting scales in Archeology. Issues of Theory and Practice (pp.183202). Nueva York: Kluwer.

» Kuhn, S. (1992). On planning and curated technologies in the middle Paleolithic. Journal of Anthropological Archaeology, 3, 185-214

» Kuhn, S. (2004). Upper Paleolithic raw material economies at Ücagizli cave, Turkey. Journal of Anthropological Archaeology, 23, 431-448.

» Llano, C. y Barberena, R. (2013). Explotación humana de especies vegetales en Patagonia, septentrional: el registro arqueobotánico de Cueva Huenul 1 (Provincia de Neuquén, Argentina). Darwiniana N.S., 1(1), 5-19.

» Llano, C., de Porras, M. E., Barberena, R., Timpson, A., Beltrame, M. O., Marsh, E. J. (en prensa). Human resilience to Holocene climate changes inferred from rodent middens in semiarid regions of northwestern Patagonia (Argentina). Palaeogeography, Palaeoclimatology, Palaeoecology.

» Llano, C., Sosa, P., Sánchez, C., Barberena, R. (2019). Arqueobotánica de Cueva Huenul 1 (Neuquén, Argentina): Selección y procesamiento de especies vegetales. Intersecciones en Antropología, 20(2), 211-223.

» Nami, H. G. (1986). Experimentos para el estudio de la tecnología bifacial de las ocupaciones tardías en el extremo sur de la Patagonia Continental. Informe de investigación. Manuscrito inédito.

» Nami, H. G. (1991). Algunas reflexiones teóricas sobre arqueología y experimentación. Shincal, 3(2), 151-168.

» Nami, H. G. (1992). El subsistema tecnológico de la confección de instrumentos líticos y la explotación de los recursos del ambiente: una nueva vía de aproximación. Shincal, 2, 33-53.

» Nelson, M. (1991). The Study of Technological Organization. Advances in Archaeological Method and Theory, 3, 57-99.

» Neme, G. y Gil, A. (2008). Biogeografía humana en los Andes meridionales: tendencias arqueológicas en el sur de Mendoza. Chungara, Revista de Arqueología Chilena, 40(1), 5-18.

»Páez, M., Quintana, F. y Pérez, C. (2004). Biogeografía de las regiones áridas y semiáridas entre $35^{\circ}$ y $39^{\circ} \mathrm{S}$, Argentina. Boletín de la Sociedad Argentina de Botánica, 39(3-4), 171-180.

»Paulides, L. S. (2006). El núcleo de la cuestión. El análisis de los núcleos en los conjuntos líticos. En C. Pérez de Micou (Ed.), El modo de hacer las cosas: artefactos y ecofactos en arqueología (pp. 67-100). Buenos Aires: Universidad de Buenos Aires.

» Pompei, M. P., Barberena, R., de Porras, M. E., Borrazzo, K., Rughini, A. y Gil, A. (2012). Late Quaternary Ecosystems and Humans in Northern Patagonia (Neuquén, Argentina). En L. Miotti, M. Salemme, N. Flengenheimer y T. Goebel (Eds.), Southbound Late Pleistocene Peopling of Latin America. Volumen Especial de Current Research in the Pleistocene (pp. 187190). Texas: Center for the Study of the First Americans, Texas A\&M University.

»Rindel, D., Perez, I. y Romero Villanueva, G. (2018). Investigaciones arqueológicas en el noreste de Neuquén: evidencias materiales y tendencias distribucionales preliminares. Intersecciones en Antropología, 19, 99-110.

» Romero Villanueva, G. (2019). Biogeografía humana y circulación de información en el norte del Neuquén. Un análisis arqueológico sobre la comunicación visual en grupos cazadoresrecolectores del noroeste de Patagonia (Tesis Doctoral inédita), Universidad de Buenos Aires, Argentina.

» Romero Villanueva, G. (2020). El arte rupestre de Cueva Huenul 1 (Neuquén, Argentina): un lugar persistente del noroeste de Patagonia. Manuscrito inédito. 
» Romero Villanueva, G. y Barberena, R. (2017). Los huesos de guanaco pintados de Cueva Huenul 1 (norte del Neuquén, Patagonia septentrional). Relaciones de la Sociedad Argentina de Antropología, XLII(2), 369-377.

» Romero Villanueva, G., Lucero, G. y Barberena, R. (2020). Andean summer-break: Rock art insights on information networks and social interaction in a desert-highland interface in northern Patagonia (South America). Cuadernos de Arte Prehistórico, 1, 89-121.

» Rughini, A., Romero Villanueva, G., Lucero, G., Cardillo, M., Borrazzo, K., Fernández, M. V., Brera, A., Frigolé, C., Castillo, A., Vitores, M., Llano, C., Garvey, R. y Barberena, R. (2020). Arqueología distribucional y biogeografía humana en un paisaje andino-patagónico. Latin American Antiquity. https://doi.org/10.1017/laq.2020.22

» Salgán, M. L. (2015). Disponibilidad, estrategias de aprovisionamiento y uso de recursos líticos en La Payunia, sur de Mendoza. Revista del Museo de Antropología, 8(2), 119-132.

»Shackley, M. S. (2005). Obsidian: Geology and Archaeology in the North American Southwest. Tucson: University of Arizona Press.

» Sherwood, S. C. (2001). Microartifacts. En P. Goldberg, V. Holliday y C. R. Ferring (Eds.), Earth sciences and archaeology (pp. 327-352). New York: Kluwer Academic/Plenum Publisher.

» Sullivan, A. P. y Rozen, K. C. (1985). Debitage analysis and archaeological interpretation. American Antiquity, 50(4), 755-779.

» Vita-Finzi, C. (1978). Archaeological Sites in their Setting. Londres: Thames and Hudson.

»Weitzel, C. y Colombo, M. (2006). ¿Qué hacemos con los fragmentos? Un experimento en fractura de artefactos líticos tallados. La Zaranda de Ideas, Revista de Jóvenes Investigadores en Arqueología, 2, 19-33. 